\title{
PROFESSORAS UNIVERSITÁRIAS NEGRAS: TRAJETÓRIAS E NARRATIVAS
}

\author{
Maria Aparecida dos Santos Crisostomo* \\ Marcos Antonio dos Santos Reigota**
}

Recebido em: 30 de novembro de 2009 Aprovado em: 10 de fevereiro de 2010

*Psicóloga; Professora. Adjunta de Psicologia Social da Universidade Paulista - Campus Sorocaba. Mestre em Educação pela Universidade de Sorocaba. E-mail: mapscris@gmail.com

**Doutor, Professor do Programa de Pós-graduação em Educação da Universidade de Sorocaba. Email: marcos.reigota@prof.uniso.br

Resumo: A presente investigação buscou analisar a condição de mulheres negras, docentes no ensino superior em universidades privadas da cidade de Sorocaba-SP, no período de 2000 a 2007, através de suas respectivas trajetórias e narrativas, articuladas em três aspectos: gênero, raça e escolaridade. Nosso objetivo foi verificar a inserção política e profissional da mulher negra, como docente, do Ensino Superior. A análise das narrativas de suas trajetórias e dos dados quantitativos que dispomos nos possibilita afirmar que a condição da mulher negra como professora universitária é a de exclusão. Um olhar atento sobre as trajetórias e narrativas de três mulheres negras, professoras universitárias na cidade de Sorocaba - São Paulo desvela uma história de neo-racismo brasileiro. Consideramos que no momento em que a mulher negra se fizer mais presente, como docente na universidade e em posições sociais e profissões em que antes não lhe era permitido, promoverá a construção de identidades diversificadas, com novos modos de existência e representações que poderão contribuir para a consolidação de uma sociedade plural.

Palavras-chave: Professoras universitárias. Negras. Trajetórias. Narrativas. Neo-racismo.

\section{BLACK FEMALE UNIVERSITY PROFESSORS: TRAJECTORIES AND NARRATIVES}

Abstract: The present research sought to examine the condition of black women professors in higher education in private universities in the city of Sorocaba - SP, from 2000 to 2007, through their respective trajectories and narratives, focused on three aspects: gender, race, schooling. Our goal was to verify the political and professional integration of black women as Higher Education professors. The narrative analysis of their trajectories and the quantitative data allow us to affirm that the condition of black women as university professors is that of exclusion. A closer look at the trajectories and narratives of three black women, university professors in Sorocaba, reveals a history of neo-racism in Brazil. We believe that when black women become more present, as professors at universities and in social positions and professions that weren't allowed before, this will promote the construction of several identities, with new manners of existence and representations that will contribute to the consolidation of a pluralistic society.

Key words: Black Female Professors . Black Women. Trajectories. Narratives. Neo-racism.

\section{INTRODUÇÃO}

Este artigo procura evidenciar o papel relevante da educação escolar na trajetória de mulheres negras na busca pelo conhecimento e presença como docente no ensino superior. Esse processo pessoal e profissional se apóia nas idéias pedagógicas freireanas que afirmam a importância do (re)conhecimen- 
to de si como processo importante na constituição dos "sujeitos da história”. (FREIRE, 2003)

A presente investigação buscou conhecer para compreender as trajetórias de mulheres negras, professoras universitárias da cidade de Sorocaba-SP, no período de 2000 a 2007. Tendo como objetivo identificar e analisar o processo de constituição da identidade destas mulheres e em que medida sofrem ou sofreram a discriminação e/ou preconceito por questões de gênero ou raça.

Nesse intento, ouvimos as suas narrativas e trajetórias, priorizando conteúdos que abordassem a questão polêmica: A mulher negra estaria ocupando esse espaço na Educação Superior, como docente? Se não está, quais os fatores que a impedem?

Nesta pesquisa, partimos da constatação de que a mulher negra está subrepresentada como docente no ensino superior e trabalhamos com a hipótese de que as que aí se encontram sofrem um processo de exclusão em decorrência das representações sociais construídas sobre a mulher em geral e sobre as mulheres negras em particular. (LOURO, 2001)

Assim, torna-se relevante buscar compreender o núcleo da questão aqui discutida:

Em que medida a reflexão sobre os efeitos do processo de construção da noção de gênero, raça e educação, poderiam contribuir para o debate em torno da identidade da mulher, professora negra na educação superior? Quais reflexões esse estudo poderia trazer para o campo da educação como um todo?

\section{A CONDIÇÃO DE VIDA DA POPULAÇÃO NEGRA NO BRASIL DA ATUALIDADE: ESTATÍSTICAS GERAIS}

O Brasil, país com população composta por 48\% de afro-descendentes conta com apenas $27 \%$ desses indivíduos cursando o ensino superior em instituições públicas e particulares. (MEC, 2004) Eles estão em minoria nos dois tipos de instituições mesmo em regiões onde essa etnia predomina (norte, nordeste e centro-oeste). Estudos da Organização dos Estados Ibero-americanos para a Educação, Ciência e Cultura (OEI) sobre os - Jovens do Brasil, apontam que entre os que se encontram na faixa dos 15 aos 24 anos, são os negros os mais atingidos pela violência.

Negros e pardos recheiam o bolsão da pobreza em nosso país e mesmo com a abolição da escravatura, perpetua-se a situação de desigualdade de renda com impacto na qualidade da educação recebida e nas condições de vida desta população. (IPEA, 2002-2005) 
Entre as mulheres negras, a desvantagem é ainda mais alarmante, principalmente na docência; essa realidade é visível no cotidiano das universidades. Nesse momento não há dados estatísticos específicos sobre mulheres negras na educação superior como discente ou docente.

Nesse sentido, Appiah (1997) defende a importância da educação como formas possíveis de mudanças sociais apontando para a relevância da pedagogia mudar de mãos. Nessas circunstâncias, pode emergir a formação de um discurso de resistência, na medida em que os súditos mudam de lugar. Esses, livres da opressão, constroem capacidades, escrevem a própria história como sujeitos. Esse simples gesto de escrever para e sobre si mesmo tem uma profunda significação política.

\section{PROFESSORAS NEGRAS NA CIDADE DE SOROCABA - SÃO PAULO: ESTATÍSTICAS LOCAIS}

Sorocaba está localizada no estado de São Paulo, a 92 quilômetros da capital, São Paulo. O censo do IBGE (2000) apontou para 493.468 habitantes, dos quais: 242.787 são homens e 250.681 mulheres. A população Sorocabana atual é de 576.312 habitantes. Atualmente, conta com oito Faculdades de Ensino Superior e seis Universidades, sendo três de ensino público, ou seja, uma cidade com quase 600.000 habitantes, conta com apenas $27 \%$ das instituições de ensino superior do sistema público. O número de professores (as) universitários (as) atuantes nessas instituições, não nos foi possível apurar.

Uma das entrevistadas desta pesquisa nos informou que na Universidade particular em que trabalha, na cidade de Sorocaba - SP, estão 328 professores no total, compostos por 191 homens e 137 mulheres. Esses dados demonstram, atuando como professores universitários nesta instituição, o contingente de $58,23 \%$ de homens e $41,77 \%$ de mulheres. Contudo, é importante destacar pelo tema deste estudo, que nesta amostra encontramos apenas 03 professoras negras exercendo a docência universitária, representando 0,91 \% em percentuais em relação aos números totais de professores (as) nesta universidade privada.

\section{TRAJETÓRIAS DAS MULHERES NA FORMAÇÃO DA SOCIEDADE BRASILEIRA: AS ÍNDIAS, AS NEGRAS E AS MISTURAS DE RAÇAS}

No Brasil, foi à falta da mulher branca que gerou uma organização cristã com a mulher indígena, recém-batizada, tomada como esposa e mãe de família. 
A mulher gentia, como era chamada, foi o solo fértil da família brasileira, nos preparos dos alimentos ainda em uso, com as drogas e remédios caseiros, nos cuidados às crianças, nos processos de higiene. Durante a escravidão as mulheres africanas de pele mais clara, mais próximas em cultura e "domesticação" dos brancos, foram às preferidas nas Minas Gerais, tomadas como "donas de casa". (FREYRE, 2003, p. 390)

No período colonial brasileiro, uma multiplicidade de fatores influenciou na constituição do papel específico da mulher naquela sociedade em formação. O encontro entre etnias, visões de mundo, hábitos e crenças diferentes foram o palco dessa organização.

Essa diferenciação foi relevante no desenvolvimento dos papéis femininos e na construção de estereótipos a serviço da sociedade colonial e estendido à historiografia. Essa trajetória de preconceitos e estigmas sociais não só se refletiam nas relações entre os sexos como exacerbavam as diferenças entre as próprias mulheres.

André (2007) afirma que os escravos africanos trazidos para o Brasil pertencentes a etnias e culturas diferentes ao serem arrancados de suas raízes e leiloados em praça pública perderam seus referenciais simbólicos de pertencimento, propiciando as várias formas de inferiorização e exclusão dos afrobrasileiros. Esses foram impedidos de estudar no período da escravidão e com o passar dos anos a condição sócio-econômica da população negra a impediu de ocupar os espaços na educação e como conseqüência os espaços de trabalho.

Esses modos de ver e classificar os negros perduram na sociedade contemporânea através das diversas práticas sociais e nos discursos cotidianos. A saída para grande parte dessa população, em nossos dias, é viver nas periferias das cidades, nos guetos, tal como nos quilombos, como se houvesse ainda uma interdição aos espaços sociais compartilhados. O negro é visto como um estranho, um desviante. Tal atitude foi gerada através da discriminação racial.

\section{A MULHER NEGRA NAATUALIDADE}

A situação da mulher negra no país é ainda mais alarmante, pois, apresenta menor nível de escolaridade, trabalha mais, porém com rendimento menor. A pobreza e a marginalidade a que é submetida a mulher negra reforça o preconceito e a interiorização da condição de inferioridade, que em muitos casos inibe a reação e luta contra a discriminação sofrida.

As mulheres negras que conquistam melhores cargos no mercado de trabalho despendem uma força muito maior que outros setores da sociedade, sendo 
que algumas provavelmente pagam um preço alto pela conquista. Pois, além da necessidade de comprovar a competência profissional, têm de lidar com o preconceito e a discriminação racial que lhes exigem maiores esforços para a conquista de uma posição e respeito profissional. A questão de gênero é, em si, um complicador, mas, quando somada à da raça, significa as maiores dificuldades para os seus agentes.

No Brasil, na atualidade, a condição da mulher negra encontra-se afetada político-histórico e culturalmente dada pelas conseqüências colonialistas, escravocratas e pelas relações complexas entre estas. Os elevados índices de analfabetismo entre mulheres pobres e negras fazem parte da nossa história das formações culturais. São heranças das normas dominantes masculinas, dos preconceitos, das perseguições da Igreja e do Estado.

São histórias de desigualdades e discriminações contra a mulher negra, apontando para fatores que se imbricam, tais como: classe social, gênero e raça. Inicialmente solicitada como objeto sexual e ventre gerador, em seguida, como ama-de-leite dos filhos da elite brasileira e posteriormente, tornar-se-iam as lavadeiras, faxineiras, empregadas domésticas e prostitutas. Destituídas de suas humanidades, têm dado com seus corpos, em todos os períodos históricos, uma garantia às suas sobrevivências.

\section{A NOÇÃO DE GÊNERO}

Louro (2001) refere que mais que contar a história do feminismo ou trazer para o debate a opressão sexista que acompanha a mulher em todo o curso da história ao enfocar o gênero como categoria de análise é necessário a revisão das teorias construídas com a proposição de uma perspectiva plural que discuta e analise as representações sociais sobre a mulher.

Almeida (1998) aponta que a noção de gênero tem sido estudada associada aos conceitos de raça e de classe social. Surgido do movimento e militância feminina assentado no reconhecimento da existência da desigualdade e, posteriormente na luta por sua eliminação. De acordo com essa perspectiva a ênfase recai sobre a igualdade na diferença. Essa perspectiva feminista permite a apropriação de uma consciência crítica e política mobilizadora na compreensão das desigualdades e sua superação requer das mulheres apreenderem os significados das divisões de gênero, de classe e raça.

Oliveira (2004) se apropria das idéias de Audad (1998) para explicitar a questão do gênero como uma categoria teórica designada pelo conjunto de 
significados, símbolos e atributos construídos na e pela história como características e diferenciações de homens e mulheres em cada sociedade.

Corroborando com as perspectivas acima citadas, Scott (1998) argumenta que as discussões sobre gênero são construções sociais e que a história da mulher é permeada pela dominação masculina, tendo o gênero como baliza na organização dessas relações. As histórias das mulheres foram tecidas nesse sistema de dominação masculina, ainda que a subjetividade e a formação do sujeito abarquem algo muito mais complexo. Não que haja uma essência feminina, mas, uma subjetividade urdida em uma conjunção peculiar da história da cultura e da política.

\section{A RAÇA COMO NOÇÃO}

A adoção de teorias raciais no Brasil requer a reflexão sobre o modelo incorporado, sobre sua serventia e o esquecimento do que não dava conta de explicitar nossas especificidades. Como é possível falarmos em "evolução humana" diferenciando as raças e negando a civilização aos negros e mestiços desprezando a realidade da miscigenação?

A concepção das teses raciais necessita ser questionada em seus significados contextuais, articulada com a situação social, política, econômica e intelectual vigentes no país de então, produzindo e reproduzindo novos valores e concepções. (SCHWARCZ, 1993)

No Brasil, a discussão sobre o racismo brasileiro carece da superação do tabu do recalque e do silêncio, do contrário cairíamos num racismo às avessas. Dado que o silêncio constrói representação capaz de servir como base ao próprio racismo no Brasil. Esse fenômeno, "manifesta-se em relação a quase todos os aspectos da vida brasileira, a começar pela educação". (NASCIMENTO, 2003, p. 23)

Munanga (2005-2006) defende que as identidades humanas são diversificadas de acordo com os modos de existência ou representação singular e própria às comunidades culturais, de língua, de sexo, às quais pertencem os indivíduos. Primeiramente, porque em nossa formação social houve o encontro de culturas e civilizações distintas. Em segundo lugar, é que o conteúdo da raça é social e político, assim não importa que a biologia e a genética afirmem a não existência da raça, uma vez que ela existe na cabeça dos racistas e suas vítimas.

O Brasil desenvolveu seu racismo assentado na negação do mesmo e, nesse contexto, os racismos contemporâneos recorrem apenas aos conceitos de diferenças culturais e identitárias. Assim, no combate ao racismo não basta à 
substituição do conceito raça pelos de etnia, de identidade ou de diversidade cultural, pois aquele: "é uma ideologia capaz de parasitar em todos os conceitos". (MUNANGA, 2005-2006, p. 53)

Autores como Schwarcz $(2005,2006)$; Pena e Birchal $(2005,2006)$ e Munanga $(2005,2006)$ comungam das idéias de que: do ponto de vista genético ou biológico não existem raças, porém, tal conceito está impregnado de ideologia, a serviço de relações de poder e dominação. Enquanto definições que produzem relações sociais, as "raças” estão nas cabeças das pessoas.

\section{AÇÃO AFIRMATIVA: O SISTEMADE COTAS NAS UNIVERSIDADES}

O Projeto de Lei de Cotas (PL n $\left.{ }^{\circ} .73 / 1999\right)$ e do Estatuto da Igualdade Racial (PL n ${ }^{\circ} .3 .198 / 2000$ ), art. 52 defende uma cota mínima de 20\% de vagas para os afro-brasileiros em todas as universidades nacionais. Essas, enquanto ações afirmativas e políticas de cotas objetivam reduzir as conseqüências do racismo historicamente construído e mantido na e pelas práticas sociais (FERREIRA; MATTOS, 2007). A partir dessa lei, reações divergentes, desencadearam dois manifestos, um contra a política de cotas, com o lema: "Todos têm direitos iguais na República democrática" de 30/05/2006 e o "Manifesto em favor da Lei de Cotas e do Estatuto da Igualdade Racial" de 03/07/2006 defendendo essa política.

Schwarcz (2005-2006) argumenta que o tema raça continua em pauta em decorrência de novos projetos sociais, de novas propostas educacionais ou mesmo por conta da implantação das cotas na universidade. Que tal debate se justifica num país como o Brasil, marcado por exercer uma espécie de "preconceito social privado”, que nega ou tenta ocultar a desigualdade e a exclusão pública, só a admitindo em âmbito privado. As medidas visando o combate da desigualdade social, assentada na idéia de exclusão social evidenciam seus efeitos perversos, principalmente, referente às condições das populações negras no Brasil.

A polêmica em torno do tema, segundo a autora, assumiu duas posições. A primeira em defesa de uma política mais universalista que privilegie a adoção de medidas "igualitárias" baseada numa matriz ibérica, recriada nos moldes brasileiros, norteado na mestiçagem e na assimilação. Esta também desqualifica a noção biológica de raça e, como conseqüência tenta banir medidas que sugerem a "racialização do tema", nesse caso, as cotas. A segunda, respaldada em autores que consideram as limitações do conceito raça, porém, defendem seu uso político, uma vez que, já está propalado no senso comum. Desta forma, para esses estudiosos, a inserção do termo raça torna-se necessário e 
"eficaz" em nossa sociedade, como uma política de "equiparação" com vistas à promoção da igualdade.

Diante do debate dicotômico entre "favor ou contra", a saída, para Schwarcz (2005-2006, p. 7), não seria simplesmente selecionar uma das opções, posto que grandes questões sejam passíveis de imprecisão e de perplexidade. Ao buscar esclarecer diferentes lados dessa polêmica não podemos perder de vista a questão das cotas imbricada em discussões muito mais amplas. Segundo a autora, a discriminação como algo inerente a nossa era globalizada, é fomentada por ódios históricos, rotulados a partir da etnia, da origem, da condição ou, "da raça". Contudo, enfatiza a relevância de um olhar voltado para a nossa realidade local.

\section{RESULTADOS E DISCUSSÕES}

Com o objetivo de investigar a condição da mulher negra entre professoras universitárias da cidade de Sorocaba-SP, no período de 2000 a 2007, encontramos para entrevistá-las, apenas três mulheres. Duas delas, atuando como docente no ensino superior e uma que após trabalhar 30 anos nesse nível de ensino, aposentou-se. Com os sujeitos disponíveis buscamos averiguar os imbricamentos das questões de gênero e raça na educação de terceiro grau, e em que medida essas mulheres sofrem ou sofreram a discriminação e/ou preconceito por questões de gênero ou raça e de que maneira esses fatores são determinantes no processo de constituição da identidade dessas mulheres.

Conforme a análise dos dados, essas agentes sociais não foram homogêneas em suas visões referentes às indagações da pesquisa. Entretanto, foi possível traçar um esboço geral dos conteúdos emergentes nas falas das entrevistadas refletidos em seus discursos. Tais conteúdos foram agrupados nas seguintes categorias: Filhas de famílias pobres; Pais com pouca escolaridade; a educação escolar como possibilidade de ascensão social; Importância da família ou um de seus membros (pai ou mãe) incentivando-as nos estudos; Discriminação de gênero e raça; Mecanismo de Formação Reativa; Ações afirmativas; Racismo oculto, preconceito velado e a Universidade como espaço de segregação.

Neste estudo verificou-se que a maioria de nossas entrevistadas são originárias de famílias pobres, como se pode verificar nas falas seguintes:

[...] a minha mãe era uma operária da fábrica de tecidos da Votorantim... minha mãe era uma mulher muito prendada. Uma mulher de certos instrumentos, né. Minha mãe era uma ótima cozinheira, ótima mãe, ótima esposa, mas ela já não era uma pessoa que tinha 
a informação, os conhecimentos que meu pai detinha. Ela detinha assim, os conhecimentos do cotidiano, né. Como bem administrar uma casa, uma mulher que bordava muito bem, que costurava muito bem, é... tricotava, cozinhava [...]. (MM)

[...] minha mãe era empregada doméstica, lavava roupa pra fora. Minha avó era lavadeira, né. A vida toda. [...] Muito pobre porque eu era... assim pra servir mesmo. Então eu tive avó lavadeira, mãe lavadeira, empregada doméstica [...]. (ES)

Para a análise das condições de vida enfrentadas por nossas entrevistadas é relevante contextualizá-las em nosso sistema de sociedade capitalista e preconceituosa. Bourdieu argumenta que na compreensão dos sofrimentos humanos é necessária a confrontação com visões de mundo diferentes e muitas vezes antagônicas, posto que fundadas em razão social. Os lugares de cada um, ditos difíceis, necessitam ser pensados sob a ótica de representações complexas e múltiplas a serviço da pluralidade dos pontos de vista. (BOURDIEU, 1997)

A inferiorização dada pela cor é como uma marca visível simbolizada historicamente e parece definir quem é o negro e qual é e não é o seu lugar, inclusive o de classe social. Nesse sentido, é que essas famílias acumulam deficiências e dificilmente conseguem mudar suas origens e quando isso ocorre não é sem muita luta e resistência. (ANDRÉ, 2007)

Nos discursos de algumas entrevistadas, a educação apresenta-se como a possibilidade de ascensão social, mas sempre com a ajuda de terceiros:

[...] Olha o que eu fui, foi assim... eu sempre fui a primeira aluna [..] E estudava muito... Muito. E a... e os professores, as pessoas em si achavam que eu era de outro planeta, porque mulher naquela época, negra... mulher... porque naquela época, mulher não estudava, então eu lembro que a patroa da minha mãe, quando ela falou:..”.Meus netos não conseguem estudar"!... me deu uniforme, caderno, tudo $[\ldots] .(E S)$

A pouca escolaridade dos pais e avós dos sujeitos desta pesquisa, também aparece como elementos marcantes e recorrentes destas trajetórias. Diante da realidade dessas famílias, a ênfase nos estudos formais como projeto futuro e condição para a ascensão social, aparecem constantemente nas falas das pesquisadas. A ênfase dada à escolarização das filhas pode ser uma estratégia encontrada por essas famílias para o enfrentamento das discriminações raciais, de gênero e preconceito. 
[...] Eu até esqueci de contar que eu fui discriminada uma vez, na segunda série do primário, por uma professora. E minha mãe foi e pôs o dedo no nariz da professora [...] e falou: "você está aqui para ensinar, e não para discriminar. Que você está chamando minha filha de macaco [...]. (MM)

[...] Então, eu senti, em primeiro lugar, uma resistência enorme por parte deles em me aceitar, [...] por ser a única mulher, também pelo fato de ser negra, [...]. (AM)

Diante do sofrimento vivido, nossas entrevistadas apresentam em seus relatos uma espécie de mecanismo defensivo do ego, cunhado por Sigmund Freud em 1926, como formação reativa. Este sintoma neurótico, aparece em certos traços rígidos, coercitivos e compulsivos de caráter da personalidade, desenvolvidos quando fracassam, ou quando chegam ao resultado oposto àquele que conscientemente visavam. (DORON; PAROT, 1998, p. 354). A formação reativa como uma "defesa bem-sucedida", exclui da consciência as idéias atuantes no conflito. Neste estudo, podemos constatar uma atitude constituída em reação ao desejo recalcado de sentido oposto ao do preconceito e exclusão racial e/ou de classes, experimentados por nossas entrevistadas. (LAPLANCHE; PONTALIS, 2001, p. 200)

[...] Eu nunca senti nenhuma relação de discriminação, de apartheid ao longo da minha vida [...]. (MM)

[...] minhas amigas iam no tal bailinho, na época, eu não podia entrar. Mas também não me doía, eu não atinava [...]. (ES)

Também foram encontradas nessas narrativas o que Lane (1995) chama de ideologia do esforço, estratégia usada como reforço pela ideologia dominante, que se de um lado afirma a igualdade dos humanos, de outro defende que é através do esforço, da dedicação e da tenacidade que uns serão mais bem sucedidos que outros. Como nos fragmentos de narrativas que se seguem:

[...] Para uns a estrela brilha mais, outros tem que ter mais suor na cara. (MM)

Aqui se evidencia o sentido da exclusão social perversa no contemporâneo, de um lado a classe dominante da sociedade buscando mostrar que os dominados são diferentes e, portanto, precisam ser segregados; e por outro lado 
os dominados que desconhecem (ou camuflam) como atuam no cotidiano, os discursos da ideologia do esforço, não se sentindo prejudicados, lutam "como se” desfrutassem das mesmas oportunidades.

$\mathrm{Na}$ atualidade, essa condição ressurge traduzida como uma face oculta do racismo no Brasil. O discurso moderno referente às relações raciais é contraditório, uma vez que no Brasil existe o preconceito. Esses mecanismos de inibição reaparecem com roupagem nova nos discursos raciais, sobretudo, com objetivo bem definido: "preservar a discriminação racial vigente desde a escravatura, assim como retirar dos cidadãos o sentimento de responsabilidade por essa situação". (CAMINO et al., 2000, p. 32)

[...] Então, é....então tanto o meu pai, quanto a minha mãe, na infância, eles não sofreram, eles não sentiram essa relação de "Casa Grande e Senzala", esse apartheid, eles não sentiram isso. Como eu também não senti na minha vida [...[. (MM)

[...] Eu não me senti diminuída, porque eu acho isso é uma coisa que graças a Deus, a minha mãe sempre trabalhou muito bem, né, em mim e nos meus irmãos, pra gente nunca se sentir menos, diminuído, que nós não éramos diferentes de ninguém [...]. (AM)

Nesse contexto teríamos o neo-racismo brasileiro. Ele não se dá a ver espontaneamente. Ele age silenciosamente através do preconceito velado. No cotidiano entre negros e brancos, secretamente mina as relações humanas.

[...] Como negra, eu [...] enfrento dificuldades o tempo todo, [...] a gente é questionado, [...] sempre tem um olhar meio de canto, [...]. (AM)

As opiniões das entrevistadas, referentes ao sistema de cotas para negros na universidade como uma política de ações afirmativas, são temerosas, pois alegam que tal política poderá gerar maiores condições de inferiorização aos indivíduos negros.

O sistema de cotas para negros no ensino superior pode ser visto como uma ruptura no universo acadêmico originado no século passado. Se por um lado, as ações afirmativas reposicionam o debate concreto das relações raciais iniciando pelos discentes, trazem consigo a semente em potencial, aos docentes e pesquisadores. Por outro lado, põe a nú questões como as interpretações das relações raciais no Brasil, estabelecidas dentro desse mundo acadêmico intensamente desigual sob o ponto vista racial. (CARVALHO, 2005-2006) 


\section{CONSIDERAÇÕES FINAIS}

O que se evidencia nesse estudo sobre a condição da mulher negra no ensino universitário privado, na cidade de Sorocaba-SP, é que a presença desta nesse nível de ensino e instituição, ainda continua pouco visível. Diante desse quadro, também a universidade é um universo de segregação racial. A realidade da opressão sofrida por essas mulheres negras, em suas trajetórias acadêmicas, desvela o mito da democracia racial no país e revela um verdadeiro apartheid no ensino superior. Mesmo tratando-se de representações específicas, a questão racial na universidade, não se afasta da realidade de outros segmentos da sociedade, como um símbolo do neo-racismo brasileiro.

A posição á favor das políticas de cotas, enquanto ações reparadoras justificam-se em decorrência de que no Brasil, houve um processo de racialização inferiorizante dos negros (as) ou não-brancos (as), de tal forma a deixá-los em desvantagem escolar concreta. Nesse caso, as próximas gerações de mulheres negras que pretendam alcançar a docência no ensino universitário terão duas possíveis saídas: ou participam e se colocam no debate sobre a racialização e as novas modalidades de racismo no Brasil, ou passarão mais alguns séculos com muito "suor na cara” e defendendo que em nosso país há igualdade de oportunidade para todos, basta desejar, e suar muito...

A mudança para esse estado de coisas requer um embate político no cotidiano da escola, no reconhecimento dessas formas de exclusões veladas, na conscientização do racismo e do sexismo reproduzido no espaço escolar. A escola como um espaço privilegiado para a convivência com as diferenças, como construtora de práticas concretas de denúncia e erradicação da exclusão em todas as esferas: de grupo social, cultural, étnico e religioso. Como assevera Reigota (2002), nesse movimento constante é que se constituem histórias sociais e individuais capazes de rupturas com visões naturalistas e essencialistas sobre as diferenças culturais e sociais de um povo.

\section{REFERÊNCIAS}

ALMEIDA, J. S. de. Mulher e educação: a paixão pelo possível. São Paulo: Unesp, 1998.

ANDRÉ, M. C. da. Processos de subjetivação em afro-brasileiros: anotações para um estudo. Psicologia: Teoria e Pesquisa, São Paulo, v. 23, n. 2, p. 159168, abr./jun. 2007. 
APPIAH, K. A. Na casa de meu pai: a África na filosofia da cultura. Rio de Janeiro: Contraponto, 1997.

AUDAD, D. Formação de professores: um estudo dos cadernos de pesquisa a partir do referencial de gênero. 1998. Dissertação (Mestrado em Educação) - Faculdade de Educação. Universidade de São Paulo, São Paulo, 1998.

BOURDIEU, P. A Miséria do mundo. 5. ed. Petrópolis: Vozes, 1997.

CAMIN0, L. et al. A face oculta do racismo no Brasil: uma análise psicossociológica. Psicologia Política, São Paulo, p. 13-36, jun. 2000.

CARVALHO, J. J. de. O confinamento racial do mundo acadêmico brasileiro. Racismo, São Paulo, p. 88-103, 2005-2006.

DORON, R.; PAROT, F. Dicionário de psicologia. São Paulo: Ática, 1998.

FERREIRA, R. F.; MATTOS, R. M. O afro-brasileiro e o debate sobre o sistema de cotas: um enfoque psicossocial. Psicologia Ciência e Profissão, São Paulo, p. 46-63, v. 27, n. 1, 2007.

FREIRE, P. Pedagogia do oprimido. 35. ed. Rio de Janeiro: Paz e Terra, 2003.

FREYRE. G. Casa grande e senzala: formação da família brasileira sob o regime da economia patriarcal. 48. ed. São Paulo: Global, 2003.

IBGE - INSTITUTO BRASILEIRO DE GEOGRAFIA E ESTATÍSTICA.

Censo 2000. Disponível em: <www.nossosaopaulo.com.br/Reg_12/Reg12_ Sorocaba.htm>. Acesso em: 30 out. 2008.

IPEA - INSTITUTO DE PESQUISA ECONÔMICA APLICADA. Políticas sociais: acompanhamento e análise. Brasília: Ipea, jun. 2002 a ago. 2005. (Boletim de Políticas Sociais). Disponível em: < http://www.ipea.gov.br/pub/ bps/bps.html>. Acesso em 30 out. 2008.

LANE, S. T. M. O que é psicologia social. São Paulo: Brasiliense, n. 39, 1995.

LAPLANCHE, J.; PONTALIS, J. B. Vocabulário de psicanálise. 4. ed. São Paulo: Martins Fontes, 2001. 
LOURO, G. Mulheres nas salas de aulas. In: PRIORE, M. (Org.). História das mulheres no Brasil. 5. ed. São Paulo: Contexto, 2001. p. 443-481

. Gênero, sexualidade e educação: uma perspectiva pósestruturalista. 4. ed. Petrópolis: Vozes, 2001.

MEC -MINISTÉRIO DA EDUCAÇÃO. Censo da educação superior, 2004.

MUNANGA, K. Negritude: usos e sentidos. São Paulo: Ática, 1988.

. Rediscutindo a mestiçagem no Brasil: identidade nacional versus identidade negra. Petrópolis, RJ: Vozes, 1999.

. Algumas considerações sobre "raça", ação afirmativa e identidade negra no Brasil: fundamentos antropológicos. Racismo. São Paulo, 46-57, 2005-2006.

NASCIMENTO, E. L. O sortilégio da cor: identidade, raça e gênero no Brasil. São Paulo: Summus, 2003.

OLIVEIRA, E. Mulher negra professora universitária trajetória, conflitos e identidade. 2004. Tese (Doutorado) - Faculdade de Filosofia, Letras e Ciências Humanas, Universidade de São Paulo, São Paulo, 2004.

PENA, S. D. J.; BIRCHAL, T. S. A inexistência biológica versus a existência social de raças humanas: pode a ciência instruir o etos social. Racismo, São Paulo, p. 10-21, 2005-2006.

REIGOTA, M. A floresta e a escola: por uma educação ambiental pósmoderna. São Paulo: Cortez, 2002.

. POSSAS, Raquel; RIBEIRO, Adalberto (Org.). Trajetórias e narrativas através da educação ambiental. Rio de Janeiro: DPe A, 2003.

SCHWARCZ, L. M. O espetáculo das raças: cientistas, instituições e questão racial no Brasil - 1870-1930. São Paulo: Companhia das Letras, 1993.

. Na boca do furacão. Racismo, São Paulo, p. 5-9, 2005-2006.

. A questão racial brasileira vista por três professores. Racismo, São Paulo, p. 167-179, 2005-2006.

SCOTT, J. W. Estudos Feministas, São Paulo, p. 114-124, v. 6, n. 1, 1998. 